\title{
Symptoms and coping in Sri Lanka 20-21 months after the 2004 tsunami
}

Michael Hollifield, Chandanie Hewage, Charlotte N. Gunawardena, Piyadasa Kodituwakku, Kalum Bopagoda and Krishantha Weerarathnege on behalf of the International Post-Tsunami Study Group

\section{Background}

The estimated prevalence of clinically significant psychiatric and somatic symptoms in adults >1 year after the 2004 Asian tsunami is unknown.

\begin{abstract}
Aims
To estimate the prevalence of psychiatric and somatic symptoms and impairment in Sri Lanka 20-21 months after the 2004 Asian tsunami, and to assess coping strategies used by tsunami-affected individuals that contribute to posttsunami adjustment.
\end{abstract}

\section{Method}

Homes from one severely affected area were randomly selected, and adult respondents were sampled utilising a modified Kish method. Instruments were administered in Sinhala to assess exposure, post-traumatic stress disorder (PTSD), depression, anxiety, somatic distress and impairment. Demographic variables and culturally-relevant coping activities were assessed.

\section{Results}

The prevalence of clinically significant PTSD, depression and anxiety was $21 \%, 16 \%$ and $30 \%$ respectively. Respondents reported a mean of eight persistent and bothersome somatic complaints, which were associated with psychiatric symptoms and impairment. Thinking that one's life was in danger was the exposure item most strongly associated with symptoms and impairment. The majority of respondents found their own strength, family and friends, a Western-style hospital and their religious practice to be the most helpful coping aids.

\section{Conclusions}

A large minority of adults in one area of Sri Lanka reported significant psychiatric and somatic symptoms and impairment 20-21 months after the tsunami. Accurate data about risk for and resilience to impairing symptoms $>1$ year after disasters are necessary in order to develop rational surveillance and interventions

\section{Declaration of interest}

None. Funding detailed in Acknowledgements.
On 26 December 2004, a tsunami ravaged regions of South Asia and East Africa. Sri Lanka was hard hit, reporting 31187 deaths, 4280 missing, 23189 injured, and 545715 displaced. ${ }^{1}$ Hundreds of first-response and psychosocial care teams converged on Sri Lanka, ${ }^{2}$ yet there are thus far only a few epidemiological health reports since the tsunami. Neuner et al found that $14-39 \%$ of a convenience sample of children met criteria for post-traumatic stress disorder (PTSD) 3-4 weeks after the disaster. ${ }^{3}$ Wickrama \& Kaspar found that $41 \%$ of adolescents and $19.6 \%$ of their mothers had PTSD 4 months after the tsunami. ${ }^{4}$ Studies from other countries report a significant prevalence of PTSD in the year following the tsunami. ${ }^{5-10}$

However, the burden of a wide range of symptoms and impairment $>1$ year after the tsunami is unknown. Manifestations of distress after a disaster are broad and not limited to PTSD. ${ }^{11}$ Furthermore, knowledge about how people with limited resources coped with symptoms is lacking. The World Health Organization estimated that approximately $5-10 \%$ of tsunami-affected people (or about 22 000-44 000 people in Sri Lanka) would develop mild or moderate common mental disorders (e.g. depression, anxiety or PTSD) in addition to the estimated $10 \%$ baseline community prevalence. $^{2}$ This prediction has not been evaluated. Our International Post-Tsunami Study Group convened to: (a) evaluate the feasibility of conducting epidemiological research in order to develop a community-based intervention in one area of a low-income country devastated by disaster; (b) conduct a focused epidemiological study; and (c) utilise study data to develop intervention research. This report presents results of the focused epidemiological study.

\section{Method}

\section{Design}

This was a cross-sectional, pilot epidemiological evaluation of anxiety, depression, PTSD and distressing somatic symptoms in one area of Southern Sri Lanka 20-21 months after the 2004 tsunami. The study was approved by research committees at the University of Louisville, USA, and the University of Ruhuna in Galle, Sri Lanka.

\section{Setting and context}

The southern province of Sri Lanka has three districts, a population of 2.3 million and was severely affected by the tsunami (>4000 deaths and 128000 displaced). Approximately one-third of the people live below the poverty level. ${ }^{12}$ The public healthcare system is resource-poor, partly owing to armed insurrections in 1971 and 1989, and a 20-year civil war from 1982 to 2002.

We determined that it was important to work in a committed way with one community for this study. Our team had an established relationship with people and reconstruction partners in the Peraliya area, which is adjacent to the main coastal road, and its people are primarily Buddhists who support themselves by fishing. Over $95 \%$ of Peraliya's structures were destroyed, 450 families became homeless, and approximately 296 inhabitants and 1500 people on a train that was traveling through the area perished when the tsunami struck. 


\section{Sample}

Damage and reconstruction rendered all previous maps of Peraliya obsolete. A new map was constructed by a project assistant and a local resident. Peraliya had 223 permanent homes and 37 known uninhabited buildings at the time of data collection in August and September, 2006. Mapped homes were assigned sequential numbers and a computer-generated random numbers list identified the order of homes from which respondents would be sampled. The number to be sampled for the study was determined using the exact variance estimation. ${ }^{13}$ One male and one female aged 18-80 years were selected after the Kish technique, ${ }^{14}$ which has been shown to be effective in obtaining representative samples in larger populations. A total of 87 homes were approached. Of these, 26 were found to be uninhabited. Demographic data were recorded for those not interested in participating to determine whether there was a sample bias. All respondents provided written informed consent.

\section{Measures}

As in our previous transcultural work (details available on request) we followed the accepted Brislin model to translate the study measures. ${ }^{15}$ The instruments were iteratively forward- then back-translated by two independent bi-lingual workers and consensus was obtained on items for content and semiotic equivalence by investigators and stakeholders. Questionnaires were administered by Sri Lankan medical school graduates trained in representative sampling, data collection and management, assisting non-literate persons and interviewing techniques.

Trauma exposure was assessed by an adapted questionnaire. ${ }^{16}$ Eight items assessed personal threat to life and personal property damage as well as injuries, property damage, and death of the respondents' family and friends. Threat to or loss of life was scored ' $0=$ no' or ' $1=$ yes'. Injury to others was scored ' $0=$ no', ' $1=$ yes, not seriously', or ' $2=$ yes, seriously'. Property damage was scored ' $0=$ none', ' $1=$ a little', ' $2=$ some damage', ' $3=$ much damage', or ' $4=$ enormous damage'.

Anxiety and depression were assessed by the Hopkins Symptom Checklist-25 (HSCL-25), which has a 10-item anxiety and a 15-item depression scale, both of which have produced valid and reliable data in the general US population and in various non-Western refugee groups. ${ }^{17,18}$ The established clinically significant item-average cut-off score of $\geqslant 1.75$ for each sub-scale was utilised in the current study, since the cross-cultural validity of the measure has been established. ${ }^{19-20}$ Test-retest reliability is high ( $r=0.89$ total, $r=0.82$ sub-scales) and the HSCL-25 predicts diagnosed depression (sensitivity $88 \%$, specificity $73 \%$ ) or the presence of any major DSM-III Axis I disorder (93\% sensitive, $76 \%$ specific) in culturally diverse refugees. ${ }^{21}$ Cronbach's alpha was 0.91 and 0.88 for the anxiety and depression sub-scales respectively in this study population.

Post-traumatic stress disorder was assessed by the Posttraumatic Stress Symptom Scale - Self Report (PSS-SR), which is a valid predictor of PTSD diagnosis in US populations ${ }^{22}$ and is strongly correlated with war-related trauma and concurrent psychopathology in Vietnamese and Kurdish refugees. ${ }^{23}$ The scale's 17 items, each scored from 0 to 3 for symptom frequency, are DSM-IV PTSD diagnostic items. The PSS-SR is scored as continuous ( 1 to $9=$ mild; 10 to $19=$ moderate; $\geqslant 20=$ severe) or dichotomous as a proxy PTSD diagnosis. Cronbach's alpha is 0.91 and 1-month test-retest reliability is 0.74 for the overall scale. In this study population, Cronbach's alpha was 0.90 .

Somatic symptoms were assessed by the New Mexico Refugee Symptom Checklist-121 (NMRSCL-121), ${ }^{24}$ developed in our research to assess symptoms in traumatised non-Western populations. The somatic scale has 39 items, each scored from 0 (not at all) to 4 (extremely) regarding the 'persistent and bothersome' nature of the symptom over the past year. During focus groups we determined that an adapted 41-item scale was appropriate for Sri Lanka. Scoring is a sum of positive items. Cronbach's alpha is 0.98 for the NMRSCL-121, and 4- to 6-week test-retest correlation is 0.81 . For the 41 somatic items $\alpha=0.95$ in this study population.

Impairment was assessed by the Sheehan Disability Inventory. This measure has three 10-point rating scales that assess impairment in work, social and home/family life, and a 0 to 5 global disability scale. ${ }^{25}$ The Sheehan Disability Inventory has been used extensively in research and its scale alpha coefficients range from 0.56 to 0.86 .

Socio-demographic variables assessed include gender, age, educational level, marital status, religious affiliation and level of religious participation. Educational level was stratified into six groups (no schooling, up to grade 5, grades 5-8, A-level, university diploma and other vocational).

The degree to which culturally relevant activities were helpful in coping with symptoms since the tsunami was assessed using questions developed in focus groups with Sri Lankan advisors. The activities identified for this pilot were:

(a) own strength;

(b) family/friends;

(c) general religious practice;

(d) Ayurveda;

(e) Western-model medical doctor/hospital/health system;

(f) religious and cultural rituals (i.e. Thovil/Methuruma, Bodhi-puja);

(g) horoscope.

Thovil and Methuruma are ritual healing ceremonies practised in Sri Lanka, and Bodhi-puja is a ceremony practised by Buddhists to venerate the Bo-tree that fulfills emotional and devotional needs. Respondents were asked to check how helpful each practice was $(0=$ not at all, $1=$ a little, $2=$ very and $3=$ extremely). One question asked how often respondents actually practised their religion $(0=$ not at all, $1=$ a little, $2=$ moderately, $3=$ very often and $4=$ daily).

\section{Data analyses}

All analyses were carried out using SPSS version 14.0 for Windows (SPSS Inc, Chicago, Illinois, USA). Prevalence estimates for traumatic exposure, symptoms, disorders and impairment were calculated. Differences by gender for prevalence and degree of symptoms, disorders and impairment were evaluated with Pearson's $\chi^{2}$ and one-way ANOVA. Bivariate correlations and ANOVA were utilised to assess associations between symptoms and impairment, exposure and symptoms and impairment, and socio-demographic variables and symptoms and impairment.

\section{Results}

The sample was 89 adults from 61 homes. Respondents' mean age was 44.5 years (s.d. $=16.3$, range $18-80)$. A total of $47(53 \%)$ were women and $42(47 \%)$ were men, $77(87 \%)$ were married and 12 $(13 \%)$ were unmarried. Age $\left(F_{1,87}=2.98, P=0.09\right)$ and educational level $\left(X_{4}^{2}=1.73, P=0.79\right)$ did not differ significantly by gender. There were 12 ( 8 men and 4 women) who refused participation (relative risk $88 \%$ ). Refusers did not reliably differ from respondents on age (36.1 v. 44.5 years, $F_{1,99}=2.90, P=0.09$ ). 


\begin{tabular}{|c|c|}
\hline & $n(\%)$ \\
\hline \multicolumn{2}{|l|}{ Life lost or at risk } \\
\hline \multicolumn{2}{|c|}{ Respondent thought their life was in danger } \\
\hline Yes & $71(80)$ \\
\hline No & $18(20)$ \\
\hline \multicolumn{2}{|c|}{ Family members lost their life } \\
\hline Yes & $45(51)$ \\
\hline No & $43(48)$ \\
\hline \multicolumn{2}{|l|}{ Friends lost their life } \\
\hline Yes & $71(80)$ \\
\hline No & $16(18)$ \\
\hline \multicolumn{2}{|l|}{ Injury to others } \\
\hline \multicolumn{2}{|c|}{ Family members not living with respondent injured } \\
\hline Yes, seriously & $31(35)$ \\
\hline Yes, not seriously & $27(30)$ \\
\hline No & $30(34)$ \\
\hline \multicolumn{2}{|l|}{ Friends injured } \\
\hline Yes, seriously & $40(45)$ \\
\hline Yes, not seriously & $33(37)$ \\
\hline No & $13(15)$ \\
\hline \multicolumn{2}{|l|}{ Property damage ${ }^{a}$} \\
\hline \multicolumn{2}{|c|}{ Damage to own household property and belongings } \\
\hline Enormous damage & $67(75)$ \\
\hline Much damage & $20(23)$ \\
\hline Some damage & $2(2)$ \\
\hline \multicolumn{2}{|c|}{ Damage to the property and belongings of family members } \\
\hline Enormous damage & $68(76)$ \\
\hline Much damage & $19(21)$ \\
\hline Some damage & $1(1)$ \\
\hline \multicolumn{2}{|c|}{ Damage to the property and belongings of friends } \\
\hline Enormous damage & $64(72)$ \\
\hline Much damage & $21(24)$ \\
\hline Some damage & $3(3)$ \\
\hline
\end{tabular}

\section{Trauma exposure}

A total of $80 \%$ thought their life was in danger during the tsunami, while $51 \%$ lost a family member and $80 \%$ lost a friend (Table 1). A significant minority had family and friends who had sustained serious injury. Over $95 \%$ experienced 'much' or 'enormous' amounts of damage to personal property. There were no reliable differences between men and women on any exposure variable.

\section{Symptoms and impairment}

A quarter of respondents had moderate or severe PTSD symptoms (Table 2). Total PTSD score did not differ disgnificantly by gender, nor did the number of respondents scoring above the cut-off for clinically significant depression. Significantly more women than men scored above the cut-off for anxiety and had more somatic symptoms.

Women and men reported similar levels of impairment in their work (mean 3.1 v. 2.8, $F_{1,87}=0.2, P=0.6$ ), social life (mean 3.0 v. 3.4, $F_{1,87}=0.4, P=0.6$ ), family life (mean 2.8 v. 2.6, $\left.F_{1,87}=0.1, P=0.8\right)$ and on the global disability scale within the Sheehan Disability Inventory (mean 2.5 v. 2.6, $F_{1,87}=0.4, P=0.5$ ) due to symptoms and problems related to the tsunami. A total of $54(61 \%)$ respondents scored either 1 or 2 (mild), $22(25 \%)$ scored 3 (moderate), and $13(15 \%)$ scored 4 or 5 (severe) on the global disability scale. Post-traumatic stress disorder, depression, anxiety and somatic symptom scores all correlated with each of the three impairment scales on the Sheehan Disability Inventory (range $r=0.22$ to $r=0.44$ ).

Age, marital status and education were not associated with PTSD, depression, anxiety, somatic symptoms or impairment. Gender was not associated with impairment.

\section{Association between somatic and psychiatric symptoms}

Somatic symptom scores significantly correlated with PTSD $(r=0.56)$, depression $(r=0.58)$, and anxiety $(r=0.69)$ symptom scores. Respondents who met the proxy PTSD diagnosis reported more somatic symptoms than those not diagnosed with PTSD (mean 15.2 v. 5.8, $F_{1,87}=22.6, P<0.01$ ). Severity of PTSD was associated with somatic symptoms (no PTSD $=4.7$ symptoms, mild PTSD $=5.6$ symptoms, moderate PTSD $=14.8$ symptoms and severe PTSD $=16.5$ symptoms; $F_{1,87}=9.8, P<0.01$ ). Likewise, those above the cut-off score for significant depression and anxiety reported more somatic symptoms than those below the cut-score (depression: mean 14.6 v. $6.5, F_{1,87}=12.1, P<0.01$; anxiety: mean 14.6 v. $\left.4.8, F_{1,87}=34.6, P<0.01\right)$.

\begin{tabular}{|c|c|c|c|c|c|c|c|c|c|c|c|}
\hline \multirow[b]{2}{*}{ Respondents } & \multicolumn{5}{|c|}{ Post-traumatic stress disorder (PSS-SR) } & \multicolumn{2}{|c|}{$\begin{array}{c}\text { Depression }^{a} \\
\text { (HSCL-25) }\end{array}$} & \multicolumn{2}{|c|}{$\begin{array}{l}\text { Anxiety }^{\mathrm{b}} \\
\text { (HSCL-25) }\end{array}$} & \multicolumn{2}{|c|}{$\begin{array}{c}\text { Somatic symptoms } \\
\text { (NMSCL-41) }\end{array}$} \\
\hline & $\begin{array}{c}\text { Total } \\
\text { score } \\
\text { Mean (s.d.) }\end{array}$ & $\begin{array}{l}\text { Mild }^{\mathrm{C}} \\
n(\%)\end{array}$ & $\begin{array}{c}\text { Moderate }{ }^{d} \\
n(\%)\end{array}$ & $\begin{array}{l}\text { Severe } \\
n(\%)\end{array}$ & $\begin{array}{c}\text { Proxy } \\
\text { diagnosis } \\
n(\%)\end{array}$ & $\begin{array}{c}\text { Total } \\
\text { score } \\
\text { Mean (s.d.) }\end{array}$ & $\begin{array}{c}\text { Above } \\
\text { cut-off } \\
n(\%)\end{array}$ & $\begin{array}{c}\text { Total } \\
\text { score } \\
\text { Mean (s.d.) }\end{array}$ & $\begin{array}{c}\text { Above } \\
\text { cut-off } \\
n(\%)\end{array}$ & $\begin{array}{l}\text { Number } \\
n \text { (s.d.) }\end{array}$ & $\begin{array}{c}\text { Severity } \\
\text { Mean (s.d.) }\end{array}$ \\
\hline $\begin{array}{l}\text { Total } \\
(n=89)\end{array}$ & $6.9(7.7)$ & $50(56.2)$ & $16(18.0)$ & $6(6.7)$ & $19(21.3)$ & $21.6(7.2)$ & $14(15.7)$ & $15.9(6.5)$ & $27(30.3)$ & $7.8(8.5)$ & $15.6(21.6)$ \\
\hline $\begin{array}{l}\text { Female } \\
(n=47)\end{array}$ & $8.0(8.7)$ & $23(48.9)$ & $10(21.3)$ & $4(8.5)$ & $12(25.5)$ & $22.5(7.4)$ & 9 (19.1) & $17.8(7.1)$ & $19(40.4)$ & $9.8(9.1)$ & $20.7(24.9)$ \\
\hline $\begin{array}{l}\text { Male } \\
(n=42)\end{array}$ & $5.7(6.3)$ & $27(64.3)$ & $6(14.3)$ & $2(4.8)$ & $7(16.7)$ & $20.6(7.0)$ & $5(11.9)$ & $13.9(5.2)$ & $8(19.0)$ & $5.6(7.2)$ & $9.9(15.6)$ \\
\hline $\begin{array}{l}\text { Male } v \text {. } \\
\text { female }\end{array}$ & $\begin{array}{c}F_{1,87}=2.0 \\
P=0.20\end{array}$ & & $\mathrm{X}_{1}^{2}=2.2, P$ & $P=0.52$ & $\begin{array}{c}X^{2}{ }_{1}=1.0 \\
P=0.30\end{array}$ & $\begin{array}{c}F_{1,87}=1.7 \\
P=0.20\end{array}$ & $\begin{array}{c}X^{2}{ }_{1}=0.9 \\
P=0.30\end{array}$ & $\begin{array}{l}F_{1,87}=8.5 \\
P=0.005\end{array}$ & $\begin{array}{c}X^{2}{ }_{1}=4.8 \\
P=0.03\end{array}$ & $\begin{array}{c}F_{1,87}=5.6 \\
P=0.02\end{array}$ & $\begin{array}{c}F_{1,87}=5.8 \\
P=0.02\end{array}$ \\
\hline \multicolumn{12}{|c|}{$\begin{array}{l}\text { HSCL-25, Hopkins Symptom Checklist }-25 \text {; NMSCL-41, New Mexico Refugee Symptom Checklist }-41 \text {; PSS-SR, Post-traumatic Stress Symptom Scale - Self report; PTSD, } \\
\text { post-traumatic stress disorder. } \\
\text { a. HSCL-25: 'clinically significant' }=\text { item average } \geqslant 1.75 \text { for each scale. Depression scale had } 15 \text { items, thus total score } \geqslant 26.25=\text { clinically significant. } \\
\text { b. } \text { HSCL-25: 'clinically significant' = item average } \geqslant 1.75 \text { for each scale. Anxiety scale had } 10 \text { items, thus total score } \geqslant 17.50=\text { clinically significant. } \\
\text { c. Score between } 1 \text { and } 9 \text {. } \\
\text { d. Score between } 10 \text { and } 19 . \\
\text { e. Score } \geqslant 20 \text {. }\end{array}$} \\
\hline
\end{tabular}


Table 3 Association of trauma exposure with symptoms and impairment

\begin{tabular}{|c|c|c|c|c|c|c|c|c|c|}
\hline & \multirow[b]{2}{*}{$\begin{array}{c}\text { PTSD } \\
\text { symptoms }\end{array}$} & \multirow[b]{2}{*}{$\begin{array}{c}\text { PTSD } \\
\text { diagnosis }\end{array}$} & \multirow[b]{2}{*}{$\begin{array}{l}\text { Depression } \\
\text { symptoms }\end{array}$} & \multirow[b]{2}{*}{$\begin{array}{l}\text { Anxiety } \\
\text { symptoms }\end{array}$} & \multirow[b]{2}{*}{$\begin{array}{c}\text { Severity of somatic } \\
\text { symptoms }\end{array}$} & \multicolumn{4}{|c|}{ Sheehan Disability Inventory scales } \\
\hline & & & & & & Work & Social & Family & Global \\
\hline Life in danger & $0.28^{* *}$ & $0.26^{*}$ & 0.09 & $0.23^{*}$ & 0.14 & 0.15 & $0.26^{*}$ & $0.28^{*}$ & $0.26^{*}$ \\
\hline Death of family & $0.23^{*}$ & 0.18 & $0.27 * *$ & 0.05 & 0.04 & -0.14 & 0.16 & 0.01 & 0.06 \\
\hline Death of friend & 0.14 & 0.02 & -0.09 & -0.03 & -0.02 & -0.01 & 0.08 & -0.03 & 0.04 \\
\hline Injury to family & $0.32^{\star \star}$ & $0.26^{*}$ & 0.07 & 0.12 & -0.01 & -0.16 & 0.15 & -0.10 & -0.01 \\
\hline Injury to friend & 0.06 & 0.01 & -0.08 & -0.12 & -0.11 & -0.07 & 0.10 & -0.03 & -0.02 \\
\hline \multicolumn{10}{|l|}{ Property damage } \\
\hline Own & -0.15 & 0.01 & 0.10 & 0.12 & -0.07 & 0.12 & 0.14 & 0.09 & 0.07 \\
\hline Family & -0.02 & -0.07 & -0.17 & 0.01 & -0.11 & -0.09 & 0.04 & -0.08 & -0.06 \\
\hline Friend & 0.00 & -0.11 & -0.16 & -0.04 & -0.03 & -0.12 & 0.03 & -0.20 & -0.16 \\
\hline
\end{tabular}

\section{Association between trauma exposure and symptoms/impairment}

Three exposure items were significantly correlated with symptoms and/or impairment: thinking that one's life was in danger, and injury to family members and death of a family member. Although somatic symptoms were associated with psychiatric symptoms, they were not correlated with trauma exposure. Resilience against symptoms was also significant. For example, while all 19 respondents who met criteria for PTSD diagnosis thought their life was in danger, 52 of $71(73 \%)$ who thought their life was in danger did not have PTSD.

\section{Coping}

The majority of respondents reported that it was either 'very' or 'extremely' helpful to utilise their own strength (70\%), family and friends $(56 \%)$, a Western-style hospital $(56 \%)$ or their own religious practice $(53 \%)$ to cope with symptoms or feelings since the tsunami. This same was said of Bodhi-puja by $44 \%$, Ayurveda by $21 \%$, horoscope by $18 \%$ and Thovil/Methuruma by $3 \%$. Women utilised their religious practice more often than men (mean 3.62 v. 3.07, $F_{1,87}=9.59, P<0.01$ ), and found Bodhi-puja (mean 1.53 v. $0.81, F_{1,87}=10.69, P<0.01$ ) and Thovil/Methuruma (mean 0.28 v. $0.07, F_{1,87}=3.66, P=0.06$ ) more helpful than did men. The majority of coping practices were not associated with symptoms or impairment. However, the use of one's own religious practice was associated with being above the cut-off score for significant anxiety $(r=0.32)$ and the PSTD diagnosis $(r=0.24)$; in addition, the use of Thovil/Methuruma was associated with the PTSD diagnosis $(r=0.25)$.

\section{Discussion}

The primary finding of this focused epidemiological study was a high prevalence of a wide range of symptoms and impairment in Sri Lankan adults 20-21 months after the 2004 tsunami devastated their area. We estimate that $40 \%$ had significant mild or moderate common mental disorders (e.g. depression, anxiety or PTSD), which is higher than the $5-10 \%$ tsunami-related prevalence plus the estimated $10 \%$ baseline community prevalence predicted by the World Health Organization. ${ }^{2}$ On average, respondents were also experiencing eight persistent and bothersome somatic symptoms, which were strongly associated with depression, anxiety and PSTD. Those with psychiatric or somatic symptoms were more likely to be impaired in their daily life functions. These findings need to be viewed in the context of the high exposure, the cultural and trauma-related backdrop in Sri Lanka, post-tsunami studies from other countries and study limitations.

\section{Complexity of exposure and symptoms}

Traumatic exposure was high for most survivors, yet three of our exposure items were only modestly correlated with symptoms and impairment, perhaps because a thorough evaluation of exposure was not the focus of this study. Data about exposure and risk for psychopathology are abundant, and the assessment of disaster exposure is a specific and challenging research area. ${ }^{26-29}$ It is possible that the uniformly high exposure was the reason that gender effects were modest, which stands in contrast to the more common finding that women are twice as likely as men to develop PTSD after trauma. The effect size (Cohen's $d$ ) of PTSD score differences between women and men was small to moderate $(d=0.30)$. It has been hypothesised that, in situations of extreme trauma, gender effects may be negligible, ${ }^{30}$ similar to the negligible effect of gender on major depression with higher levels of stress. ${ }^{31}$ However, it may be that this kind of disaster confers similar gender risk, which is known to vary by trauma type. ${ }^{32,33}$

The high prevalence of symptoms and impairment may be partly due to an interaction between the effects of the tsunami and the stress of poverty and war. There is a known association between poverty and risk for PTSD in both Western and African countries. ${ }^{34,35}$ Somasundaram \& Sivayokan found that civilians in northern Sri Lanka experienced frequent war-related stress, and over $25 \%$ were diagnosed with somatisation, PTSD, anxiety and depression. ${ }^{36}$ Our sample is impoverished and has also experienced war trauma, although perhaps not as severe as that faced by northern Sri Lankans. Thus, the high prevalence of criterion-level PTSD, anxiety, depression and somatic distress in our study may be in part due to a higher community baseline rate than that suggested by the World Health Organization. This higher rate might be due to the cumulative effects of 'trauma on trauma' in Sri Lanka. ${ }^{37}$

The current data are similar to recently published studies from other disasters that indicate that psychiatric symptoms may remain high for years after the primary incident. ${ }^{38-45}$ Most of these studies are limited by non-random sampling and/or low or uncertain response rates. However, Karakaya et al found a $22 \%$ prevalence of probable PTSD and a $31 \%$ prevalence of depression in a random sample of adolescents 3.5 years after an earthquake. ${ }^{42}$ Basoglu et al diagnosed 23\% with PTSD and 16\% with depression in a random sample of adults 14 months after an earthquake. ${ }^{38}$ A study of the Buffalo Creek Dam disaster found the prevalence of PTSD to be $44 \%$ soon after the incident and 
28\% 14 years later. ${ }^{46}$ Extant data show that PTSD symptoms for approximately half of those affected will abate in the first year after disaster, whereas those who have symptoms lasting for 1 year or more are likely to stay disabled for years. ${ }^{47}$ It also appears that rates of PTSD $>1$ year after disasters are strikingly similar between events (range $21 \%$ in our study to $28 \%$ in other studies), although there are data suggesting that between $7 \%$ and $67 \%$ of people exposed to mass trauma will develop PTSD. ${ }^{48}$

\section{Culturally relevant coping}

The secondary finding was that respondents coped with symptoms and distress by utilising a number of culturally relevant resources, the most common being their own strength, family and friends, the use of a Western-style hospital and their own religious practice. Our study did not evaluate access to or use of mental healthcare, although $56 \%$ said that a hospital was helpful. These findings indicate a need for services that augment current coping practices. That a few coping practices were associated with PTSD and anxiety does not indicate that these practices are harmful. These data are cross-sectional, so it is possible that those with more anxiety are rightly seeking culturally appropriate coping activities that may be helping over time. A longitudinal study is required to evaluate the utility of these particular coping activities on symptoms and impairment.

\section{Findings contextualised}

Our findings should be contextualised by the study's limitations. First, the sample was from one area in Sri Lanka. A larger study in multiple areas would be necessary to assess whether Peraliya is representative of Sri Lanka. Second, although the PTSD symptoms reported were likely to be due to the tsunami since the instructions on the PSS-SR were tsunami-specific, depression and anxiety was likely to be confounded by pre-existing psychopathology and prior events which were not evaluated. Third, there are many reports of somatic symptoms after disasters, ${ }^{49}$ and such symptoms may have complex causes and meanings. Somatic complaints are common in everyday life and checklists are notoriously poor at diagnosing somatoform disorders. Furthermore, people with somatoform disorders are highly suggestible and report higher rates of trauma than those without such disorders. It is unlikely that a definitive diagnosis of somatoform disorder can be reliably made after a disaster. Only two studies were able to compare pre- and post-disaster epidemiological data for their samples. One showed that disaster exposure was modestly associated with the development of new somatoform symptoms, ${ }^{50}$ and the other found no increase in somatoform disorders. ${ }^{51}$ None the less, somatic complaints do occur post-disaster, are associated with psychiatric symptoms and impairment, and may be the primary focus of distress, particularly for those with pre-existing somatoform disorders. ${ }^{49}$

Perhaps the most important potential limitation of our study is the use of self-report instruments that were initially developed in other countries. Limited validity of measures will limit the accuracy of epidemiological findings. ${ }^{52}$ The PSS-SR has demonstrated limited internal and concurrent validity in Kurdish and Vietnamese refugees. ${ }^{23}$ The HSCL-25 has excellent test-retest reliability and good validity in predicting diagnosed depression in three Indochinese refugee groups. ${ }^{21}$ These previous transcultural studies coupled with our use of recommended translation methods, and the good internal reliability of the measures with this population, provide good evidence for the validity of the measures in the study setting.
Finally, assessment of coping was limited, since the primary aim of this study was to determine prevalence of symptoms. However, the coping scale was determined from pre-study focus groups and met our goal of understanding how individuals utilised culturally relevant activities to cope with the symptoms they were having since the tsunami.

Notwithstanding these limitations, the aims of this study were met. The results presented and other qualitative data not reported here provide the basis for developing a community-based intervention in Peraliya. The fact that a significant percentage of the population post-disaster may require intervention is an almost overwhelming message from a public health perspective. Developing and implementing intervention models for distressing symptoms after disasters is complicated and has started to be addressed in other intervention studies and in theoretical models. (e.g. Goenjian ${ }^{40}$; further details of both studies and models are available on request).

\section{Michael Hollifield, MD, Departments of Psychiatry and Behavioral Sciences and Family and Geriatric Medicine, University of Louisville School of Medicine, Louisville, Kentucky, USA; Chandanie Hewage, MD, Department of Psychiatry, University of Ruhuna, Galle, Sri Lanka; Charlotte N. Gunawardena, PhD, Organizational Learning and Instructional Technology Program, University of New Mexico College of Education, Albuquerque, New Mexico, USA; Piyadasa Kodituwakku, MD, Department of Pediatrics, University of New Mexico School of Medicine, Albuquerque, New Mexico, USA; Kalum Bopagoda, MD, Krishantha Weerarathnege, MD, Department of Psychiatry, University of Ruhuna, Galle, Sri Lanka. \\ Correspondence: Michael Hollifield, Department of Psychiatry and Behaviora Sciences, University of Louisville School of Medicine, $501 \mathrm{E}$. Broadway, Suite 340 Louisville, KY 40202, USA. Email: m.hollifield@louisville.edu}

First received 28 March, final revision 13 August 2007, accepted 30 August 2007

\section{Acknowledgements}

We thank members of the International Post-Tsunami Study Group, including primary investigators, consultants (Stevan Hobfoll, Fran Norris, Teddy Warner), the Sri Lanka Ministry of Health and the non-governmental agency HELP-O. The study was partially funded by the University of Louisville's Research Initiation Grant program, which had no input to the design, methods or manuscript preparation.

\section{References}

1 Centre for National Operations. http://www.cnosrilanka.org (accessed 26 February 2005).

2 Miller G. The tsunami's psychological aftermath. Science 2005; 309: 1030.

3 Neuner F, Shauner E, Catani C, Ruf M, Elbert T. Post-tsunami stress: a study of posttraumatic stress disorder in children living in three severely affected regions in Sri Lanka. J Trauma Stress 2006; 19: 339-47.

4 Wickrama KA, Kaspar V. Family context of mental health risk in Tsunamiexposed adolescents: findings from a pilot study in Sri Lanka. Soc Sci Med 2007; 64: 713-23.

5 John PB, Russell S, Russell PS. The prevalence of posttraumatic stress disorder among children and adolescents affected by tsunami disaster in Tamil Nadu. Disaster Manag Response 2007; 5: 3-7.

6 Kumar MS, Murhekar MV, Hutin Y, Subramanian T, Ramachandran V, Gupte MD. Prevalence of posttraumatic stress disorder in a coastal fishing village in Tamil Nadu, India, after the December 2004 tsunami. Am J Public Health 2007; 97: 99-101.

7 Tang CS. Trajectory of traumatic stress symptoms in the aftermath of extreme natural disaster: a study of adult Thai survivors of the 2004 Southeast Asian earthquake and tsunami. J NerV Ment Dis 2007; 195: 54-9.

8 Thienkrua W, Cardozo BL, Chakkraband ML, Guadamuz TE, Pengjuntr W, Tantipiwatanaskul P, Sakornsatian S, Ekassawin S, Panyayong B, Varangrat A, Tappero JW, Schreiber M, van Griensven F on behalf of the Thailand PostTsunami Mental Health Study Group. Symptoms of posttraumatic stress disorder and depression among children in tsunami-affected areas in southern Thailand. JAMA 2006; 296: 549-59.

9 Vijayakumar L, Kannan GK, Daniel SJ. Mental health status in children exposed to tsunami. Int Rev Psychiatry 2006; 18: 507-13.

10 van Griensven F, Chakkraband ML, Thienkrua W, Pengjuntr W, Lopes Cardozo B, Tantipiwatanaskul P, Mock PA, Ekassawin S, Varangrat A, Gotway C, Sabin 
M, Tappero JW on behalf of the Thailand Post-Tsunami Mental Health Study Group. Mental health problems among adults in tsunami-affected areas in southern Thailand. JAMA 2006; 296: 537-48.

11 World Health Organization. Mental Health Assistance to the Populations Affected by the Tsunami in Asia. World Health Organization, 2007.

12 Gunawardena L. A Proposal for the Reconstruction of Tsunami Affected Units of the University of Ruhuna Teaching Hospitals in Galle, Sri Lanka. University of Ruhuna, 2005

13 Levy PS, Lemeshow S. Sampling for Health Professionals. Lifetime Learning Publications, 1980.

14 Kish L. Survey Sampling. Wiley, 1965

15 Brislin RW. Back-translation for cross-cultural research. J Cross Cult Psychol 1970; 1: 187-216.

16 Norris F, Perilla J, Riad J, Kaniasty K, Lavizzo E. Stability and change in resources, stress, and psychological distress following natural disaster: findings from Hurricane Andrew. Anxiety Stress Coping 1999; 12: 363-96.

17 Derogatis LR, Lipman RS, Rickels K, Uhlenhuth EH, Covi L. The Hopkins Symptom Checklist (HSCL): A Measure of Primary Symptom Dimensions. In Modern Problems in Pharmacopsychiatry (ed P Basel). Karger, 1974.

18 Winokur A, Winokur DF, Rickels K, Cox D. Symptoms of emotional distress in a family planning service: stability over a four-week period. Br J Psychiatry 1984; 144: 395-9.

19 Butcher JN. Psychological evaluation. In Mental Health Services for Refugees (eds J Westermyer, C Williams, A Nguyen): 111-22. Government Printing Office, 1991.

20 Kinzie JD, Manson SM. The use of self-rating scales in cross-cultural psychiatry. Hosp Community Psychiatry 1987; 38: 190-6.

21 Mollica RF, Wyshak G, de Marneffe D, Khuon F, Lavelle J. Indochinese versions of the Hopkins Symptom Checklist-25: a screening instrument for the psychiatric care of refugees. Am J Psychiatry 1987; 144: 497-500.

22 Foa EB, Riggs DS, Dancu CV, Rothbaum BO. Reliability and validity of a brief instrument for assessing post-traumatic stress disorder. J Trauma Stress 1993; 6: 459-73.

23 Hollifield M, Warner TD, Jenkins J, Sinclair-Lian N, Krakow B, Eckert V, Karadaghi $\mathrm{P}$, Westermeyer J. Assessing war trauma in refugees: properties of the Comprehensive Trauma Inventory-104 (CTI-104). J Trauma Stress 2006; 19: $527-40$.

24 Hollifield M, Warner T. The New Mexico Refugee Symptom Checklist (NMRSCL) Questionnaire. University of New Mexico, 2000.

25 Sheehan D. The Anxiety Disease. Scribner, 1983.

26 Benight CC, Ironson G, Durham RL. Psychometric properties of a hurricane coping self-efficacy measure. J Trauma Stress 1999; 12: 379-86.

27 O'Neill HK, Evans BA, Bussman MD, Strandberg DK. Psychological distress during the Red River Flood: Predictive utility of the conservation of resource model. Appl Behav Sci Rev 1999; 7: 159-69.

28 Sumer N, Karanci AN, Berument SK, Gunes H. Personal resources, coping self-efficacy, and quake exposure as predictors of psychological distress following the 1999 earthquake in Turkey. J Trauma Stress 2005; 18: 331-42.

29 Verger $\mathrm{P}$, Rotily M, Hunault C, Brenot J, Baruffol E, Bard D. Assessment of exposure to a flood disaster in a mental-health study. J Expo Anal Environ Epidemiol 2003; 13: 436-42.

30 Nemeroff CB, Bremner JD, Foa EB, Mayberg HS, North CS, Stein MB. Posttraumatic stress disorder: a state-of-the-science review. J Psychiatr Res 2006; 40: 1-21.

31 Kendler KS, Kuhn J, Prescott CA. The interrelationship of neuroticism, sex and stressful life events in the prediction of episodes of major depression. Am J Psychiatry 2004; 161: 631-6.

32 Kessler RC. Posttraumatic stress disorder: the burden to the individual and to society. J Clin Psychiatry 2000; 61 (suppl 5): 4-12.
33 Kessler RC, Sonnega A, Bromet E, Hughes M, Nelson CB. Posttraumatic stress disorder in the national comorbidity survey. Arch Gen Psychiatry 1995 52: $1048-60$

34 Carey PD, Stein DJ, Zungu-Dirwayi N, Seedat S. Trauma and posttraumatic stress disorder in an urban Xhosa primary care population: prevalence, comorbidity, and service use patterns. J Nerv Ment Dis 2003; 191: 230-6.

35 Kiser LJ. Protecting children from the dangers of urban poverty. Clin Psychol Rev 2007; 27: 211-25.

36 Somasundaram D, Sivayokan S. War trauma in a civilian population. $\mathrm{Br} J$ Psychiatry 1994; 165: 524-7.

37 Ozgediz D, Adams JE, Dicker RA. Trauma on trauma. Lessons from the tsunami and civil conflict in Sri Lanka. Pharos Alpha Omega Alpha Honor Med Soc 2007; 70: 28-33.

38 Basoglu M, Kilic C, Salciolu E, Livanou M. Prevalence of posttraumatic stress disorder and comorbid depression in earthquake survivors in Turkey: an epidemiological study. J Trauma Stress 2004; 17: 133-41.

39 Bland SH, Valoroso L, Stranges S, Strazzullo P, Farinaro E, Trevisan M. Longterm follow-up of psychological distress following earthquake experiences among working Italian males: a cross-sectional analysis. J Nerv Ment Dis 2005; 193: 420-3.

40 Goenjian AK, Walling D, Steinberg AM, Karayan I, Najarian LM, Pynoos R. A prospective study of posttraumatic stress and depressive reactions among treated and untreated adolescents 5 years after a catastrophic disaster. Am Psychiatry 2005; 162: 2302-8.

41 Kadri N, Berrada S, Douab S, Tazi I, Moussaoui D. Post-traumatic stress disorder in survivors of the Agadir earthquake (Morocco) in 1960. [French]. Encephale 2006; 32: 215-21.

42 Karakaya I, Agaoglu B, Coskun A, Sismanlar SG, Yildiz Oc O. The symptoms of PTSD, depression and anxiety in adolescent students three and a half years after the Marmara earthquake. [Turkish]. Turk Psikiyatri Dergisi 2004; 15 257-63.

43 Livanou M, Kasvikis $\mathrm{Y}$, Bapoðlu M, Mytskidou $\mathrm{P}$, Sotiropoulou V, Spanea $\mathrm{E}$, Mitsopoulou T, Voutsa N. Earthquake-related psychological distress and associated factors 4 years after the Parnitha earthquake in Greece. Eur Psychiatry 2005; 20: 137-44.

44 Liu A, Tan H, Zhou J, Li S, Yang T, Wang J, Liu J, Tang X, Sun Z, Wen SW. An epidemiologic study of posttraumatic stress disorder in flood victims in Hunan China. Can J Psychiatry 2006; 51: 350-4.

45 North CS, Kawasaki A, Spitznagel EL, Hong BA. The course of PTSD, major depression, substance abuse, and somatization after a natural disaster. J Nerv Ment Dis 2004; 192: 823-9.

46 Briere J, Elliott D. Prevalence, characteristics, and long-term sequelae of natural disaster exposure in the general population. J Trauma Stress 2000; 13: $661-79$.

47 Shalev AY, Tuval-Mashiach R, Hadar H. Posttraumatic stress disorder as a result of mass trauma. J Clin Psychiatry 2004; 65(Suppl 1): 4-10.

48 Norris FH, Friedman MJ, Watson PJ. 60,000 disaster victims speak: Part II. Summary and implications of the disaster mental health research. Psychiatry 2002; 65: 240-60.

49 North CS. Somatization in survivors of catastrophic trauma: a methodological review. Environ Health Perspect 2002; 110(Suppl 4): 437-40.

50 Escobar JL, Canino G, Rubio-Stipec M, Bravo M. Somatic symptoms after a natural disaster: a prospective study. Am J Psychiatry 1992; 149: 965-6.

51 Robins LN, Fishbach RL, Smith EM, Cottier LB, Solomon SD, Goldring E. Impact of disaster on previously assessed mental health. In Disaster Stress Studies: New Methods and Findings (ed JH Shore). American Psychiatric Association, 1986

52 Hollifield M, Warner TD, Lian N, Krakow B, Jenkins JH, Kesler J, Stevenson J, Westermeyer J. Measuring trauma and health status in refugees: a critical review. JAMA 2002; 288: 611-21. 